\title{
REVIEW
}

\section{Micromotions and combined damages at the dental implant/bone interface}

\author{
Shan-Shan Gao, Ya-Rong Zhang, Zhuo-Li Zhu and Hai-Yang Yu
}

Micromotion and fretting damages at the dental implant/bone interface are neglected for the limitation of check methods, but it is particularly important for the initial success of osseointegration and the life time of dental implant. This review article describes the scientific documentation of micromotion and fretting damages on the dental implant/bone interface. The fretting amplitude is less than $30 \mu \mathrm{m}$ in vitro and the damage in the interface is acceptable. While in vivo, the micromotion's effect is the combination of damage in tissue level and the real biological reaction.

International Journal of Oral Science (2012) 4, 182-188; doi:10.1038/ijos.2012.68; published online 21 December 2012

Keywords: dental implant; fretting damage; micromotion

\section{INTRODUCTION}

The written record on dental implant was from $\mathrm{AD}$ 1000. The research on dental implant was not in the form of trial and error until the 1970s, and the theory system of dental implant was still blank. In the 1960s and 1970s, these progresses and breakthroughs in dental implant are based on the concept of osseointegration first described by Brånemark et al. ${ }^{1}$ Osseointegration refers to the direct contact histologically between living bone and the surfaces of commercially pure titanium implants, which is believed to provide rigid fixation of a dental implant within the alveolar bone and promote the long-term success of dental implants. ${ }^{2-3}$ So, in the past several decades, implant therapy with the replacement of missing teeth by implant-supported prostheses has expanded to become a widely accepted treatment modality for the rehabilitation of fully and partially edentulous patients.

Osseointegration is the premise of the success of dental implant; however, the direct contact between the implant surface and the surrounding bone tissue makes it possible to occur the mobility at the bone/implant interface. ${ }^{4}$ Primary mobility is the key factor of early osseointegration, and mobility of the implant is also the cardinal sign of implant failure after the osseointegration. The implant's mobility can be divided into macromobility, micromobility and micron-mobility according to Perona et al..$^{5}$ Macromobility $(>0.5 \mathrm{~mm})$ can be observed by naked eye, which means failure of osseointegration even in the absence of other signs or symptoms. But micromobility $(0.1-0.5 \mathrm{~mm})$ cannot be observed by naked eye, and need to be checked by specific instruments. Micron-mobility $(<0.1 \mathrm{~mm})$ in dental implant cannot be checked by most of the specific instruments. When the mobility amplitude is less than $100 \mu \mathrm{m}$, the micromotion is called fretting.

Fretting refers to a special wear process that occurs at the contact area between two materials under load and subject to minute relative motion by vibration or some other force. ${ }^{6}$ According to the definition, fretting would occur inevitably in dental implant/bone interface during mastication for suffering from the alternating occlusal force. In fact, fretting was found to be a problem of load-bearing implants (hip, knee), especially when modular in design and employing different materials. In contrast, fretting had not yet been observed in dental implants in $1986 .{ }^{6}$ In 2004, Zhou proposed that fretting would occur at the dental implant system, including the implant/bone interface, and other interior interfaces in dental implant system. ${ }^{7}$

Why fretting in dental implant interface would be ignored in previous research? The amplitude of fretting is generally less than $0.1 \mathrm{~mm}$. It exists during the process of developing micromobility and the immediate loading of the early stage. Just because it completely cannot be checked by naked eye, the effect is always ignored in previous research. At present, the evaluation of functional dynamics on dental implant/bone interface is introduced, including cutting resistance/ insertional torque, periotest, resonance frequency analysis, and so on. ${ }^{8}$

Considering the structure of dental implant/bone interface, similar example can be found in fastening bolt. In engineering industry, most of the fastening bolt failed for the fretting damage. There are some degrees of micron-movement at the bone/implant interface during normal functions in vivo after the host bone grows in close contact to the implant metal. ${ }^{9}$ The similar type of damage can be discovered at the fastening bolt and dental implant/bone interface (Table 1).

Although fretting exists in industry fastening screw and dental implant/bone interface, enormous differences between the two kinds of conditions lie in that the bone around dental implant is bioactive material. Therefore, the effect of fretting on bone is not simply the damage as the fastening screw. The biomechanical effect caused by fretting is not simply the damage of the bone tissue, but stimulate the cell signal pass way and produce the biological effect. Therefore, this paper reviews the research on fretting effect and biology response of dental implant/bone interface to fretting. 
Table 1 The comparison of industry fastening bolt and dental implant/bone interface

\begin{tabular}{|c|c|c|c|}
\hline \multirow[b]{2}{*}{ Interfaces } & \multirow[b]{2}{*}{ Necessary conditions for fretting } & \multicolumn{2}{|c|}{ The outcome of fretting } \\
\hline & & Wear & Fatigue \\
\hline Interface in industrial fasteners & $\begin{array}{l}\text { Oscillatory movement (micrometer) } \\
\text { Nominally static }\end{array}$ & $\begin{array}{l}\text { Loss of material } \\
\text { Loose of components }{ }^{34}\end{array}$ & $\begin{array}{l}\text { Crack initiation and expansion, reducing } \\
\text { fatigue life of components }{ }^{35}\end{array}$ \\
\hline Implant/bone interface & $\begin{array}{l}\text { Oscillatory movement (less than } 0.2 \mathrm{~mm} \text { ) } \\
\text { Clinical acceptable stability }\end{array}$ & Bone loss/absorption & Micro \\
\hline
\end{tabular}

\section{THE CLASSIFICATION OF FRETTING IN DENTAL IMPLANT}

According to the direction of relative movement, fretting in industry can be divided into four basic modes: tangential fretting, radial fretting, rotational fretting and torsional fretting. ${ }^{10}$ The combination of any two kinds of fretting modes composes the dual-motion fretting. But the fretting mode at the implant/bone interface is different from that in industry. The fretting mode in dental implant was decided by several factors: the direction of the load and the shape of dental implant surface (Figure 1). Implants with different shapes would have different fretting modes. ${ }^{11}$ Due to the existence of natural dental cusps, dental implants mainly suffer from vertical and inclining occlusal force during functional movement. But in some special cases, tangential force occurs at the lateral movement. ${ }^{11}$ According to these analyses, the fretting in dental implant/bone interface can be divided into three types: tangential fretting, radial fretting and dual-motion fretting. What effect would be produced in the interface under different fretting modes will be discussed in the following.

\section{THE EFFECT OF FRETTING MODE ON IMPLANT/BONE INTERFACE IN VITRO}

\section{Tangential fretting}

Tangential fretting is the simplest type for fretting research. Therefore, the in vitro tangential fretting experiment mode of implant/bone interface was set up at the earliest. The contact mode of implant surface to bone surface in vivo was simplified to a titanium ball-on-bone flat configuration in vitro in order to analysis the damage mechanism of the interface ${ }^{12}$ (Figure 2). Bone flat was made by exposing the cross-section. Tangential fretting produced by mastication in oral was stimulated by using a reciprocating horizontal tribometer on a modified fretting friction and wear rig in vitro (model DS 20; Nene Corp., Lyon, France.). The contact stress in vitro was similar to the real value in vivo. The imposed load was $90 \mathrm{~N}$. The displacement was set from 1 to $45 \mu \mathrm{m}$ with increment scale of $2 \mu \mathrm{m}$; frequency $f=2 \mathrm{~Hz}$; and number of cycles $N$ : 1-10 000 times. The friction $\operatorname{logs}\left(F_{\mathrm{t}}-D-N\right.$ curves $)$ were calculated and analyzed. The worn scars on cortical bone were observed by means of laser confocal scanning microscopy (OLS 1100; Olympus Corp., Tokyo, Japan).
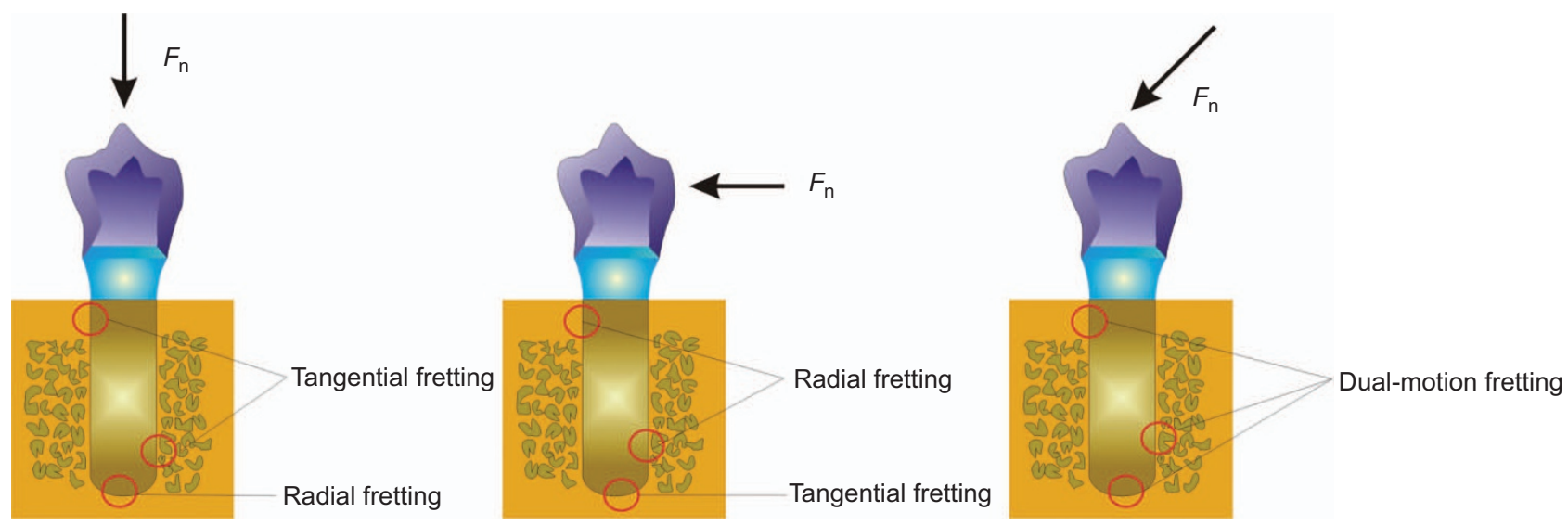

Figure 1 Fretting modes existed in the dental implant/bone interface. 


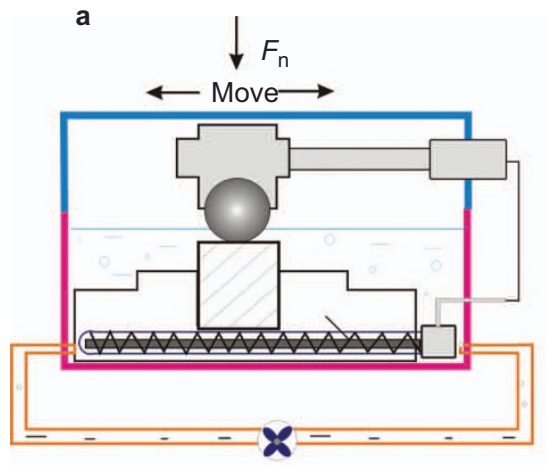

b

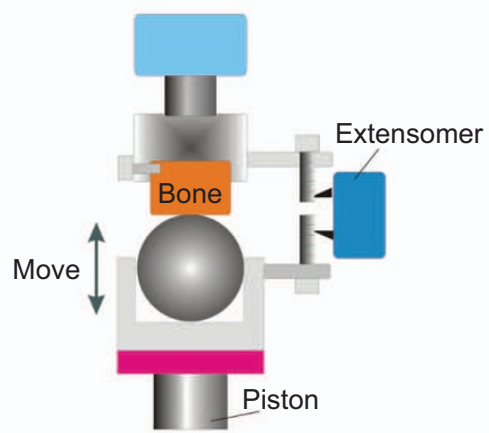

c

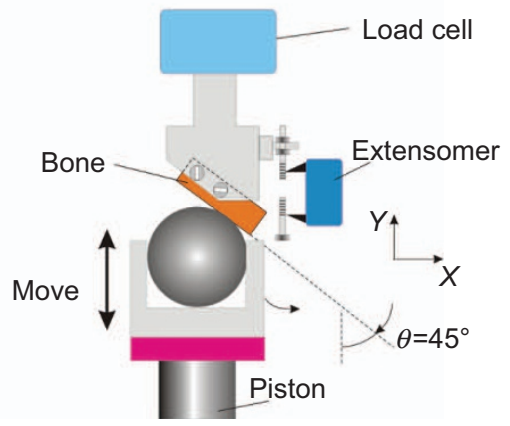

Figure 2 Schematics of fretting test on cortical bone against titanium. (a) Tangential fretting; (b) radial fretting; (c) dual-motion fretting.

$F_{\mathrm{t}}-D-N$ curve is a complete fretting test data, which refer to the variations of tangential force $v s$. displacement amplitude as a function of fretting cycles. ${ }^{13}$ At a very small displacement of $5 \mu \mathrm{m}$, the friction $\log$ of straight linear mode shows the closed $F_{\mathrm{t}}-D$ cycles (Figure 3 ). With the increase of the displacement $(D=10$ and $20 \mu \mathrm{m})$, elliptical $F_{\mathrm{t}}-D$ cycle is observed and the curves are opened with the increased displacements. When the displacement increases to $30 \mu \mathrm{m}$, elliptical $F_{\mathrm{t}}-D$ cycle transforms to quasi-rectangular $F_{\mathrm{t}}-D$ cycle. The transformation of linear mode to elliptical $F_{\mathrm{t}}-D$ cycle and quasi-rectangular elliptical $F_{\mathrm{t}}-D$ cycle reflects the obvious elastic-plastic feature of cortical bone. When the displacement is small, the displacement can be accommodated by elastic deformation of cortical bone, but with the increase of displacement, once the displacement cannot be accommodated by elastic deformation of cortical bone, plastic deformation would take place in the interface. This reflects the elastic-plastic feature of cortical bone. ${ }^{12,14}$

The fretting damages in the partial slip $(D=5 \mu \mathrm{m}$, elastic deformation) are slight because the relative motion at the interface is well coordinated by the contact interface elastic deformation. When the friction log goes into the partial slip ( $D=10 \mu \mathrm{m}$, plastic deformation), adhesion lies in the central zone of wear scar, while the damage is mainly at the contact border of wear scar. In the gross slip regime $(D=30 \mu \mathrm{m})$, the wear scar reaches the maximum dimension with the highest contact stress in the central zone of worn scars, in which the central darkish area is the sever worn area with many microcracks perpendicular to the orientation of sliding direction and even parallel microfeatures are observed (Figure 4). After the cyclic loading, the delamination of cortical bone is observed due to the propagation and coalescence of microcracks. The ploughs are shown on the border region of wear scar with relative slight damage than those of central zone. Abrasive wear characterized the mechanism of wear of cortical bone. Therefore, the tangential fretting damages of cortical bone are the coordination of delamination and abrasive wear. ${ }^{12}$ Except for the tangential displacement, imposed load can also be another important factor to influence the tangential fretting behavior.

Cortical bone around the dental implant is anisotropic material. Therefore, the different sections of cortical bone would have different tangential fretting behavior. Tangential fretting occurred at the
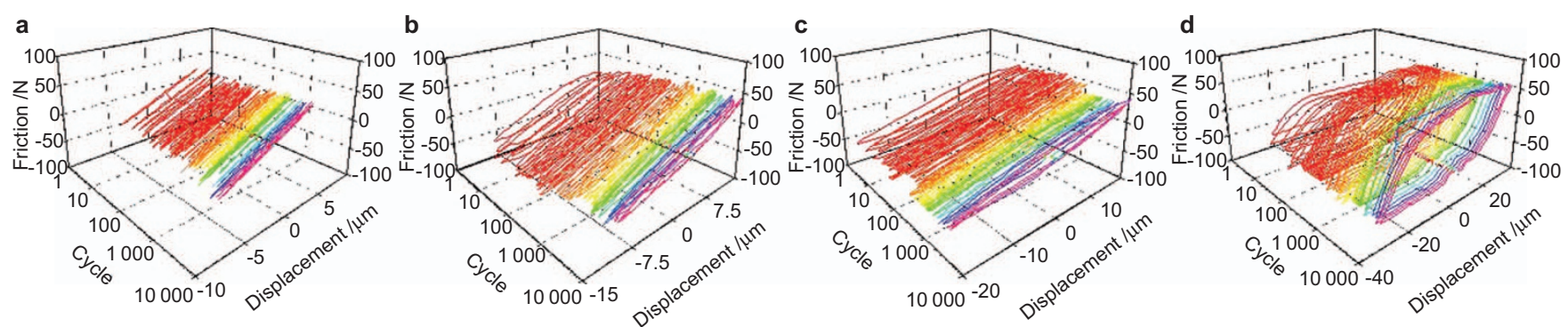

Figure 3 Friction logs of cortical cross-section-TA2 pairs under tangential fretting wear $\left(\boldsymbol{F}_{\mathbf{n}}=90 \mathbf{N}\right)$. (a) $D=5 \mu \mathrm{m}$; (b) $D=10 \mu \mathrm{m}$; (c) $D=20 \mu \mathrm{m}$; (d) $D=30 \mu \mathrm{m}$.
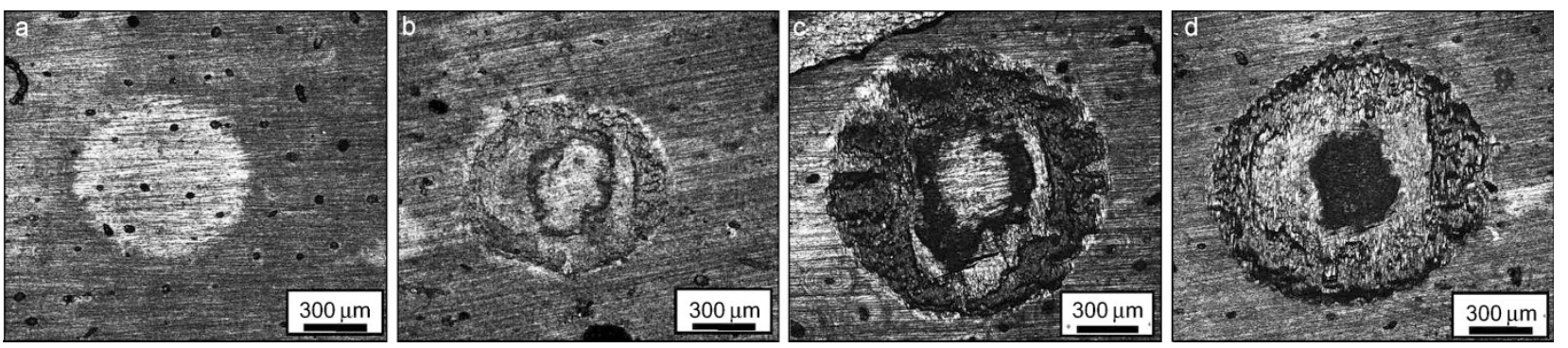

Figure 4 LCSM morphology of wear scars on cortical bone with various displacements for bone-TA2 pairs. (a) $D=5 \mu \mathrm{m}$; (b) $D=10 \mu \mathrm{m}$; (c) $D=20 \mu \mathrm{m}$; (d) $D=30 \mu \mathrm{m}$. $F_{\mathrm{n}}=90 \mathrm{~N}, N=10000$ cycles. Sliding direction is in the orientation of up and down. LCSM, laser confocal scanning microscopy. 

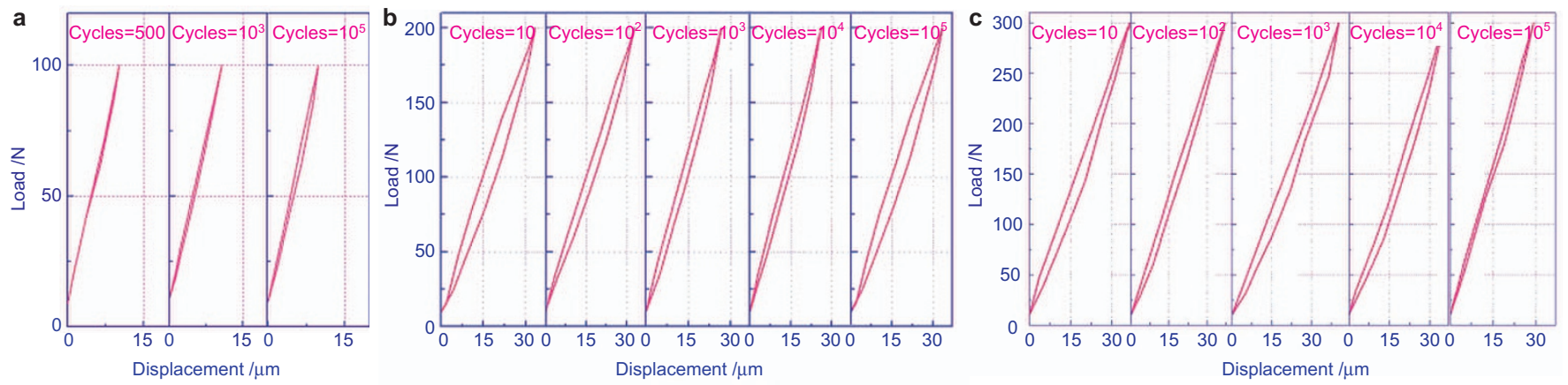

Figure 5 The $\boldsymbol{F}-\boldsymbol{D}$ curves of cortical bone against TA2 ball. (a) Under the load of $100 \mathrm{~N}$; (b) under the load of $200 \mathrm{~N}$; (c) under the load of $300 \mathrm{~N}$.

vertical section of cortical bone has similar behavior with the cross-section. But the resistance tangential behavior is better than the cross-section. ${ }^{14}$

\section{Radial fretting}

The formation of radial fretting is completely different from the tangential fretting. The imitating of radial fretting is somewhat the same to the studies on compression fatigue of bone. ${ }^{15}$ In order to simulate the condition of implants in vivo, the tests were implemented on the servo hydraulic dynamic test machine (DS20; Nene Corp.) with a ballon-flat contact configuration. The flat cortical bone specimen was fixed on the upper holder linked to the load cell. The titanium ball specimen was fixed on the lower holder and mounted on the piston, which was subjected to oscillatory movement with a given speed of $12 \mathrm{~mm} \cdot \mathrm{min}^{-1}$. The cyclic deformations between two surfaces in contact were measured by the extensometer.

The obtained $F-D$ curves indicate that under the small load $(F=100 \mathrm{~N})$, the $F-D$ curve starts as linearity (Figure $5 \mathrm{a})$. And after 500 cycles, the linear curve is opened slightly. With the increase in cycles, the maximal displacement decreases and the area under the curve increases in succession. During the process, elastic deformation on the surface of the cortical bone turns to the elastic-plastic deformation.

When the load increases to $200 \mathrm{~N}$ (Figure 5b), the curves are closed with non-overlapping status. As the cycles increase, the maximal displacement decreases and the area under the curve appears. The surface of the cortical bone is in an adjustment of elastic-plastic coordination. The deformation and the dissipated energy turn down. In the 10000 cycles, the slope rate of the curve decreases, which is caused by the material surface hardening formed in the elaborating process. With the increase of the load (Figure 2c), the deformation and area under the curve increase. It means that deformation and dissipated energy shows an increasing manner as the load increases. With the high stress, the surface of the cortical bone shows a notable plastic deformation. The curve is closed after the initial five cycles and the coordination of elastic and plastic deformation starts. The displacement and the dissipated energy act in a decreasing manner as the cycles increase. During the process, crest value of the curve appears at around 1000 cycles. Then the displacement and the dissipated energy gradually decrease. It may be caused by the crack inanition and following propagation under such load. ${ }^{16}$

The cracks in radial fretting formed in four patterns (Figure 6). The cracks which propagate along the cement line are the most popular cracks. It might be the lower contents of calcium and phosphate in the area of cement lines, which offers an interface to release the stress of propagation of cracks. The second cracks initiate from or end at the Havers's canal. The third ones are cracks connecting two consecutive Havers's canals if the stress is big enough. Each Harvers's system is a relative independent structure, but it will release the stress energy to adjacent Harvers's system if it could not use out the high stress brought from cracks alone. The fourth type is that kind of cracks propagating at interstitial lamella linearly. ${ }^{17}$

\section{Dual-motion fretting}

Dual-motion fretting in vitro could be modified from the radial fretting test through changing the clasp inclined at an angle $\theta$ of $45^{\circ}$ to the direction of piston movement ${ }^{11}$ (Figure 2). The selected parameter was similar to that of the radial fretting. At the same time, the $F-D$ curve can be obtained from the dual-motion fretting.

In fact, this kind of dual-motion fretting is essentially composed of tangential and radial fretting modes. Therefore, the $F-D$ curve shapes are induced by a superposition of tangential and radial fretting. All the $F-D$ curves are opened (Figure 7 ); it indicates that no pure elastic deformation occur under the test conditions of current materials and parameters. Under the maximal vertical load of $100 \mathrm{~N}$, there are only elliptic F-D curves before 700 cycles. The elliptic $F-D$ curves reflect that the elastic-plastic deformation occurs on the contact zone and relative slip of the tangential fretting component is in the partial slip regime. At the moment, microslip occurs at the edge of contact zone, while sticking area is in the
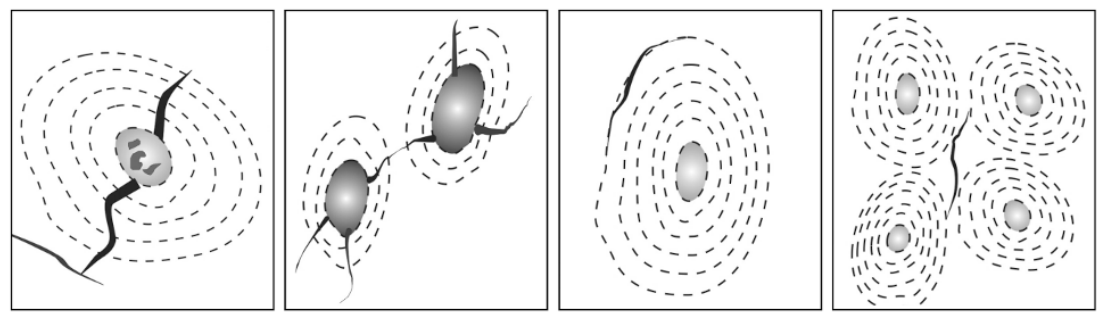

Figure 6 Four kind of cracks in radial fretting test. 
a

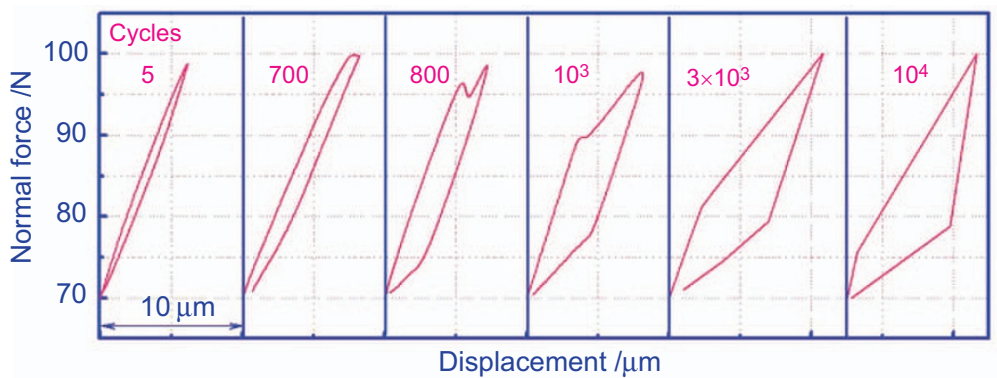

b

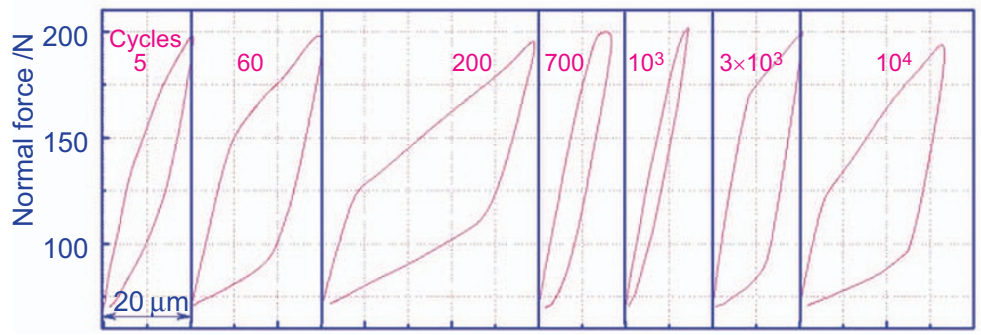

Displacement $/ \mu \mathrm{m}$

Figure 7 F-D curve under the dual-motion fretting. (a) Under the load of $100 \mathrm{~N}$; (b) under the load of $200 \mathrm{~N}$.

center of contact zone. When the number of cycles increases to 700 , a critical condition which the relative motion transform from the partial slip to the gross slip was reached, while the elliptic $F-D$ curve mutate to the trapezoid $F-D$ curve and keep this shape until the testing is finished. The trapezoid $F-D$ curves indicate the tangential component of dual-motion fretting getting into the gross slip regime. According to the theory of fretting map, the tangential fretting component is running in the regime of mixed fretting under this test condition.

Even at the early stage of the testing, no elliptic $F-D$ curve could be observed under the load of $200 \mathrm{~N}$. Therefore, the dual-motion fretting processes run in the condition of plastic deformation. The number of cycles varies from 5 to 1000 ; the values of static friction force of trapezoid cycle fluctuate in a great range: increase, decrease and increase again (Figure 7). Different displacements of the $F-D$ curves indicate the relative motion states change with the fretting cycles.

Some microcrack forms by brittle fractures due to the accumulation of plastic deformations. There are more apparent plastic deformations and macrocracks at the side of high-stress zone. At the same time, there is a great deal of the human bone tissue debris (HBTD) which distributes on the contact zones and accumulates at the contact edges (Figure 8).

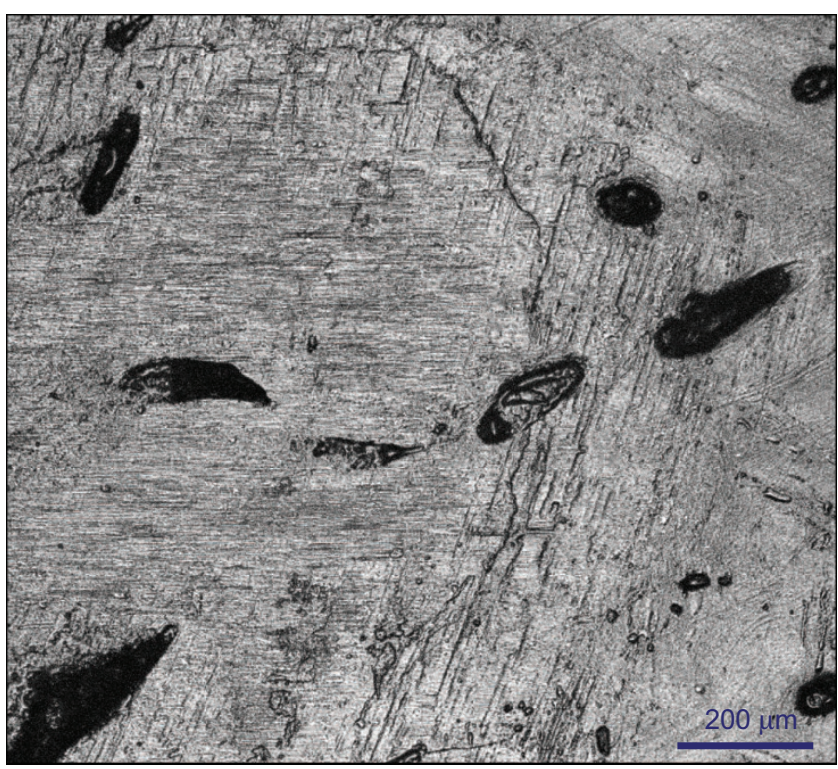

Figure 8 LCSM morphologies of the dual-motion fretting scars in the early stage under $\boldsymbol{F}_{\max }=\mathbf{2 0 0} \mathbf{N}$ and $\boldsymbol{N}=10^{4}$ cycles. LCSM, laser confocal scanning microscopy. 
Table 2 The comparison of cortical bone damages under radial and dual-motion fretting

\begin{tabular}{|c|c|c|}
\hline Items & Radial fretting & Dual-motion fretting \\
\hline Damage mechanism & Plastic deformation and microcracks & Plastic deformation, microcracks, delamination and abrasive wear \\
\hline Propagation of cracks & $\begin{array}{l}\text { Cracks distribute in edge of the scar, which were affected by } \\
\text { the microstructure of cortical bone }\end{array}$ & Cracks distribute in one side with higher stress \\
\hline Degree of damage & Slight & Severe \\
\hline Performing difficulty & Easy to carry out and analyze & Difficult to finish and analyze \\
\hline Application & $\begin{array}{l}\text { Easy to evaluate the anisotropy of material and the cracks } \\
\text { propagation of brittle material }\end{array}$ & Affected by many influencing factors, difficult to analyze \\
\hline
\end{tabular}

\section{Comparison between radial fretting and dual-motion fretting features}

Considering the similar test method and test parameters, the difference behavior between radial fretting and dual-motion fretting can becompared. Therefore, the comparison tests were produced by Gao et al. group. ${ }^{18}$

They found the disparity in degree of damage, the initiation and propagation of microcracks. And they summarized the compare of cortical damages under radial and dual-motion fretting (Table 2).

Fretting behavior of implant/bone interface in vitro can reflect the damage which occurs in the interface. Therefore, the mobility was classified by $\mathrm{Yu}$ et al. according to the fretting damage; when fretting amplitude is less than $10 \mu \mathrm{m}$, there is no obvious damage, the fretting can be called tiny fretting; when fretting amplitude is more than $30 \mu \mathrm{m}$, damage is very sever, and the fretting is called intolerant fretting. When fretting amplitude falls in between 10 and $30 \mu \mathrm{m}$, the fretting is called tolerant fretting. ${ }^{1,12,14-18}$

\section{THE EFFECT OF FRETTING ON IMPLANT/BONE INTERFACE IN VIVO}

The in vitro research that can stimulate the real oral environment and oral parameters is very scarce. Most of the in vivo experiments explore the micromotion's effect on the implant/bone interface. The in vivo research on the effect of micromotion on the interface can be divided into three stages.

Early stage studies indicated that the micromotion produced by early loading would induce fibrous tissue encapsulation. ${ }^{19-21}$ The researchers found not only that micromovements were inducing fibrous tissue interposition, but also that subsequent immobilization was able to lead to a reverse tissue differentiation. ${ }^{19-20}$ And the authors concluded that initial biomechanical forces during the healing period often cause a fibrous tissue interface between the implant and bone. ${ }^{21}$ It can be concluded that micromovements like those induced by early loading of dental implants should be avoided if osseointegration is the intention. And as stated by Branemark and collaborators, the stressfree situation during the healing period seems to be mandatory to achieve osseointegration. $^{21}$

Second stage studies indicated that the early loading does not induce fibrous tissue encapsulation. Much research demonstrated that early loaded implants can also achieve the osseointegration. ${ }^{22-23}$
Further researches proposed the point that tolerated micromotion versus deleterious micromotion. ${ }^{24} \mathrm{New}$ opinion asserted that 'excess movement' or 'excessive micromotion' affects the healing sequence leading to bone ingrowth into porous implants or to direct bone anchorage of implants. ${ }^{25-27}$ The concept of threshold micromovement was introduced in 1973 by Cameron et al. ${ }^{28}$ While they were reporting on micromovements affecting bone healing, they were also making the point that not all movements led to the unwanted fibrous tissue repair. ${ }^{29-32}$ Two different types of movements were recognized: 'micromovements and macromovements'. Micromovements at the bone/implant interface are tolerated up to a certain threshold was confirmed by Pillar et al. in $1986 .{ }^{25}$ Further research found that displacements of 500 and $150 \mu \mathrm{m}$ should be considered as excessive, ${ }^{25}$ and therefore as deleterious micromotion. For implants with a bio-inert surface, the critical threshold lies somewhere between 50 and $150 \mu \mathrm{m}$. Possibly, $100 \mu \mathrm{m}$ may be the threshold level as proposed by Brunski as a rule of thumb. ${ }^{33}$ Nevertheless, it was suggested that this threshold should be determined according to the surface state and implant design. ${ }^{25,28,33}$

In general, the effects of fretting on implant/bone interface are the combination of the damage produced in tissue level and the real biological reaction in vivo. The fretting damage in tissue level can be repaired by the living tissue to some extent. But when the fretting damage exceeds the repair ability of the living tissue, bone resorption or implant loose or other negative biological reaction would take place (Figure 9).

\section{FUTURE OUTLOOK}

No matter previous fretting research in vitro or in vivo, all the interfaces are normal bone tissues. In clinic, the patients may have hypertensions, diabetes, obesity, dysfunction of immune system or other diseases. Whether the fretting effect on the abnormal conditions is similar to previous research remains unknown. We still need to explore in our future research. Besides, the effects of fretting on cells are still not clear for the limitation of cell cycle and the real mastication frequency and time. Therefore, we still need to establish the new mode for cell research under fretting condition. The mechanism of mechanical stress produced by fretting on implant/bone interface still needs to be further elaborated. 


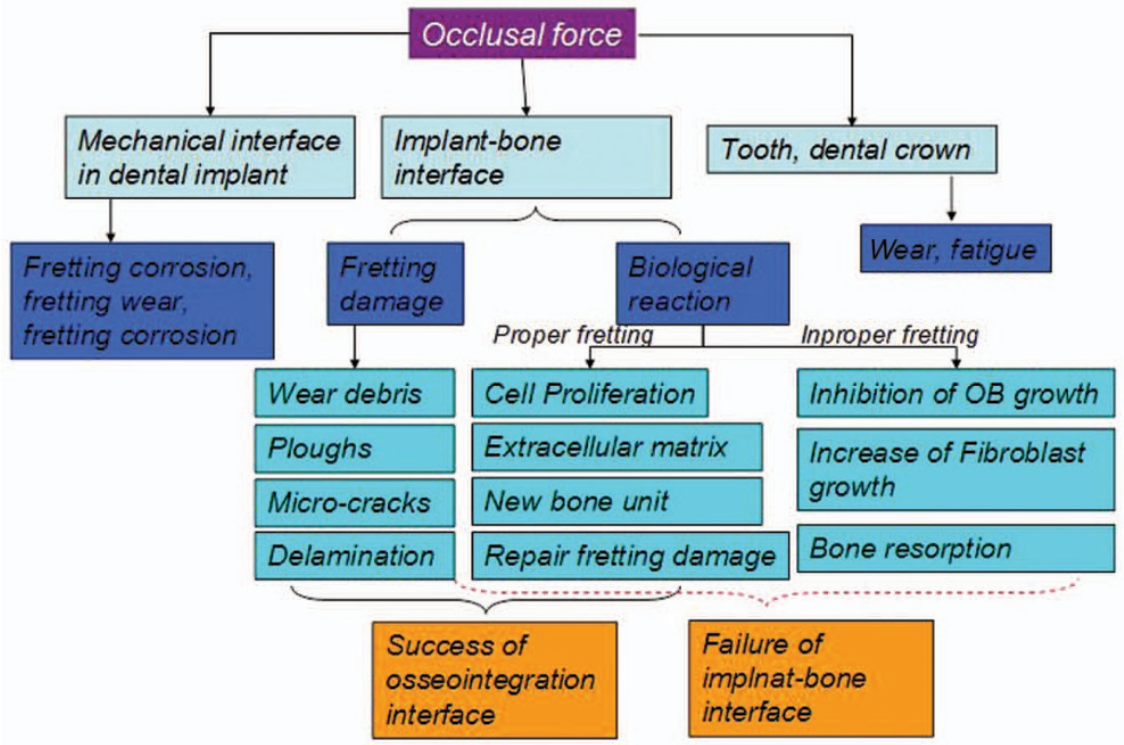

Figure 9 The effect of fretting on dental implant.

\section{ACKNOWLEDGEMENTS}

The authors acknowledge the support of the National Natural Science Foundation of China (Nos. 81170996, 81070867, and 81100777), Sichuan Province Science and Technology Innovation Team Program (2011JTD0006), and declare any industrial links or affiliations.

1 Brånemark R, Ohrnell LO, Nilsson $\mathrm{P}$ et al. Biomechanical characterization of osseointegration during healing: an experimental in vivo study in the rat. Biomaterials 1997; 18(14): 969-978.

2 Franchi M, Fini M, Martini D et al. Biological fixation of endosseous implants. Micron 2005; 36(7/8): 665-671.

3 Joos U, Wiesmann HP, Szuwart T et al. Mineralization at the interface of implants. Int J Oral Maxillofac Surg 2006; 35(9): 783-790.

4 Carlsson L, Rostlund T, Albrektsson B et al. Osseointegration of titanium implants. Acta Orthop Scand 1986; 57(4): 285-289.

5 Perona PG, Lawrence J, Paprosky WG et al. Acetabular micromotion as a measure of initial implant stability in primary hip arthroplasty. An in vitro comparison of different methods of initial acetabular component fixation. J Arthroplasty 1992; 7(4): 537-547.

6 Buchert PK, Vaughn BK, Mallory TH et al. Excessive metal release due to loosening and fretting of sintered particles on porous-coated hip prostheses. Report of two cases. J Bone Joint Surg Am 1986; 68(4): 606-609.

7 Zhou ZR, Zhu MH. Dual-motion fretting wear. Shanghai: Shanghai Jiaotong University Press, 2004.

8 Chang PC, Lang NP, Giannobile WV. Evaluation of functional dynamics during osseointegration and regeneration associated with oral implants. Clin Oral Implant Res 2010; 21(1): 1-12.

9 Viceconti M, Muccini R, Bernakiewicz M et al. Large-sliding contact elements accurately predict levels of bone-implant micromotion relevant to osseointegration. J Biomech 2000; 33(12): 1611-1618.

10 Zhu MH, Zhou ZR. An experimental study on radial fretting behaviour. Tribol Int 2001; 34(5): 321-326

11 Yu HY, Gao SS, Cai ZB et al. Dual-motion fretting behavior of mandibular cortical bone against pure titanium. Tribol Int 2009; 42(9): 1365-1372.

12 Yu HY, Cai ZB, Zhou ZR et al. Fretting behavior of cortical bone against titanium and its alloy. Wear 2005; 259(7/8/9/10/11/12): 910-918.

13 Zhou ZR, Liu QY, Zhu MH et al. An investigation of fretting behaviour of several metallic materials under grease lubrication. Tribol Int 2000; 33(2): 69-74.

$14 \mathrm{Yu} \mathrm{H}$, Cai Z, Zhu M et al. [Research on fretting behaviors of axial cortical bone of femur.] Chin J Mech Eng 2005; 41(8): 149-152. Chinese.

$15 \mathrm{Yu}$ HY, Quan HX, Cai ZB et al. Radial fretting behavior of cortical bone against titanium. Tribol Lett 2008; 31(2): 69-76.

16 Cai ZB, Zhu MH, Gao SS et al. [Investigation on radial fretting behavior of human axial femur compact bone.] J Shanghai Jiaotong Univ 2008; 42(5): 707-710. Chinese.

17 Cai ZB, Gao SS, Zhu MH et al. Investigation of micro-cracking behaviors of human femur cortical bone during radial fretting. Tribol Int 2011; 44(11): 1556-1564.

18 Gao S, Cai Z, Quan H et al. Comparison between radial fretting and dual-motion fretting features of cortical bone. Tribol Int 2010; 43(1/2): 440-446.
19 Uhthoff HK, Germain JP. The reversal of tissue differentiation around screws. Clin Orthop Relat Res) 1977; (123): 248-252.

20 Soballe K, Hansen ES, B-Rasmussen $\mathrm{H}$ et al. Tissue ingrowth into titanium and hydroxyapatite-coated implants during stable and unstable mechanical conditions. J Orthop Res 1992; 10(2): 285-299.

21 Akagawa $\mathrm{Y}$, Hashimoto $\mathrm{M}$, Kondo $\mathrm{N}$ et al. Initial bone-implant interfaces of submergible and supramergible endosseous single-crystal sapphire implants. J Prosthet Dent 1986; 55(1): 96-100.

22 Deporter DA, Watson PA, Pilliar RM et al. A histological comparison in the dog of porous-coated vs. threaded dental implants. J Dent Res 1990; 69(5): 1138-1145.

23 Sagara M, Akagawa Y, Nikai $\mathrm{H}$ et al. The effects of early occlusal loading on one-stage titanium alloy implants in beagle dogs: a pilot study. J Prosthet Dent 1993; 69(3): 281-288.

24 Gapski R, Wang HL, Mascarenhas $\mathrm{P}$ et al. Critical review of immediate implant loading. Clin Oral Implant Res 2003; 14(5): 515-527.

25 Pilliar RM, Lee JM, Maniatopoulos C. Observations on the effect of movement on bone ingrowth into porous-surfaced implants. Clin Orthop Relat Res 1986; (208): 108113.

26 Wazen RM, Brunski JB, Currey JA et al. Interfacial tissue response is influenced by local strain created during implant micromotion. J Bone Mine Res 2008; 23: S234.

27 Lin CL, Chang SH, Chang WJ et al. Factorial analysis of variables influencing mechanical characteristics of a single tooth implant placed in the maxilla using finite element analysis and the statistics-based Taguchi method. Eur J Oral Sci 2007; 115(5): 408-416.

28 Cameron HU, Pilliar RM, MacNab I. The effect of movement on the bonding of porous metal to bone. J Biomed Mater Res 1973; 7(4): 301-311.

29 Freitas AC Jr, Bonfante EA, Giro G et al. The effect of implant design on insertion torque and immediate micromotion. Clin Oral Implant Res 2012; 23(1): 113-118.

30 Aspenberg P, Goodman S, Toksvig-Larsen S et al. Intermittent micromotion inhibits bone ingrowth. Titanium implants in rabbits. Acta Orthop Scand 1992; 63(2): 141 145.

31 Gratton DG, Aquilino SA, Stanford CM. Micromotion and dynamic fatigue properties of the denial implant-abutment interface. J Prosthet Dent 2001; 85(1): 47-52.

32 Fazel A, Aalai S, Rismanchian M et al. Micromotion and stress distribution of immediate loaded implants: a finite element analysis. Clin Implant Dent Relat Res 2009; 11(4): 267-271.

33 Brunski JB. Avoid pitfalls of overloading and micromotion of intraosseous implants. Dent Implant Update 1993; 4(10): 77-81.

34 Dong $\mathrm{H}$, Ju X, Yang $\mathrm{H}$ et al. Effect of ceramic conversion treatments on the surface damage and nickel ion release of NiTi alloys under fretting corrosion conditions. J Mater Sci Mater Med 2008; 19(2): 937-946.

35 Zhu MH, Yu HY, Cai ZB et al. Radial fretting behaviours of dental feldspathic ceramics against different counterbodies. Wear 2005; 259(7/8/9/10/11/12): 996-1004.

(c) This work is licensed under a Creative Commons MMEFIGHISHESERVED Attribution-NonCommercial-NoDerivative Works 3.0 Unported License. To view a copy of this license, visit http:// creativecommons.org/licenses/by-nc-nd/3.0 